Earth \& Environment | Jochen Hack

\title{
Preserving biodiverse river corridors for sustainable city development
}

As the global population continues to soar and the development strategies are urgently needed to prevent catastrophic ecological decline in our urban environments. Understanding anthropogenic conservation: Jochen Hack Professor of Ecological
Engineering at the Univ Engineering at the University leader of the interdisciplinary research group SEE-URBANWATER, utilises habitat quality assessment software to model the effects of urban the Pochote river's ecosystem ecology in Nicaragua, climbs ever higher, sustaities threats is the first step towards infrastructure and pollution on

oday's global population clocks
in at around 7.9 billion people. in at around 7.9 billion people. inhabitants live in urban areas inhabitants live in urban areas - a 2050, according to the United Nation Department of Economic and Social Affairs. Over the last 70 years, the globa urban population has grown by almost 3.5 billion people, but this growth has not been spread equally across all continents - in Africa, rural living is still the norm, with less than $50 \%$ of its population living in cities. Megacities cities with 10 million or more inhabitants are predicted to dominate the habitation landscape by 2030, with 43 of these mega-metropolises worldwide, many of
them in developing regions.

While the benefits of urbanisation include better access to jobs, healthcare and education for citizens, migration to cities is manifold. With

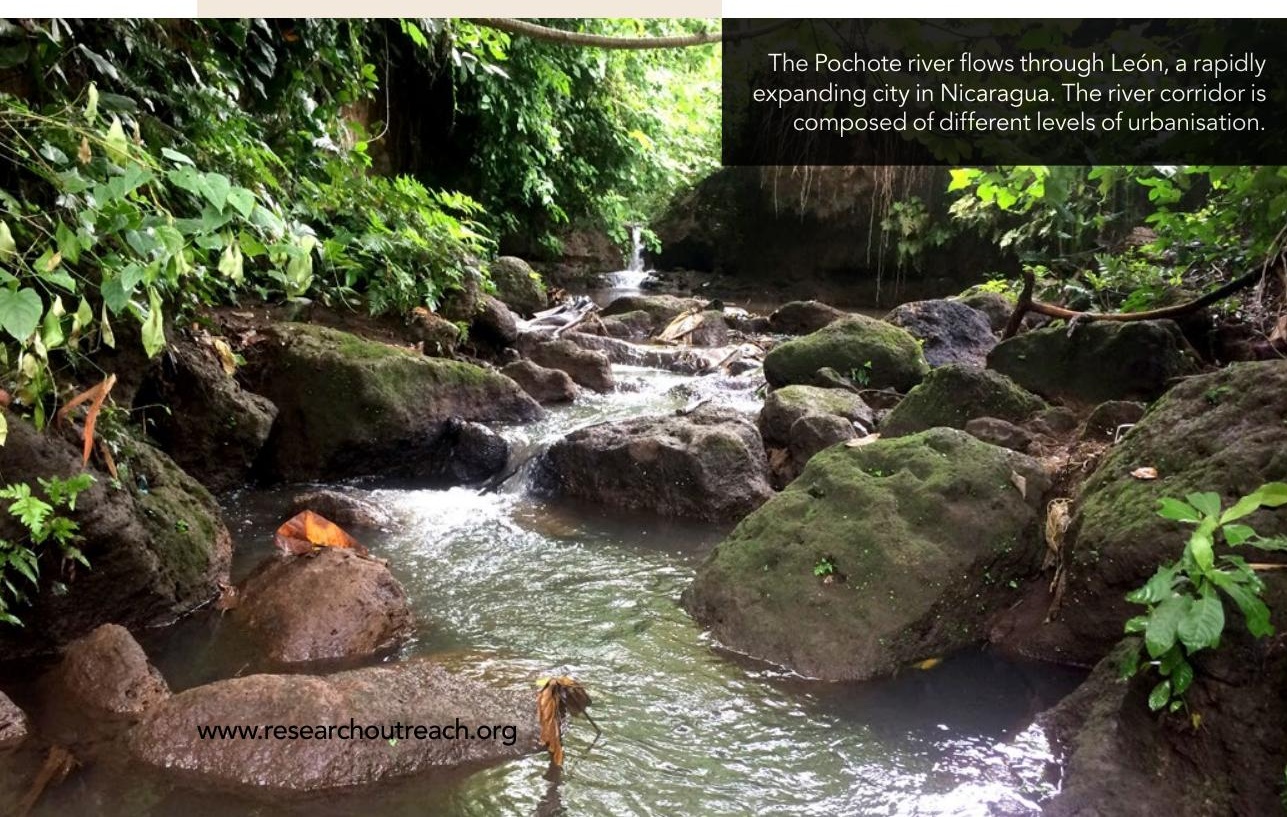

exploding populations comes the need transport millions of the wastes that they produce. Without adequate planning and management. rapid urbanisation can result in not only poor life quality for people living in cities, but wider-reaching environmental impacts, including water and air pollution, and ecological destruction.

ECOLOGICAL EXPLOITATION In 2019, a landmark report from the Intergovernmental Science-Policy Platform on Biodiversity and Ecosystem Services (IPBES) painted a stark picture af current ecological landscape. approximately $75 \%$ of the Earth's land surface has been significantly altered, 1 million species face extinction, due to human activity. The IPBES report explored how land use changes have impacted terrestrial and freshwater ecosystems, finding agricultural and urban dwelling expansion to be two of the biggest drivers of habitat degradation over the last 50 years. For freshwater ecosystems such as ivers, IPBES identified water extraction and pollution, climate change, and manmade infrastructures (road networks, oil and gas pipelines, hydroelectric dams) as principal threats causing the highest levels of decline.

Rivers play an essential part in maintaining viable ecosystems, by functioning as ecological corridors -

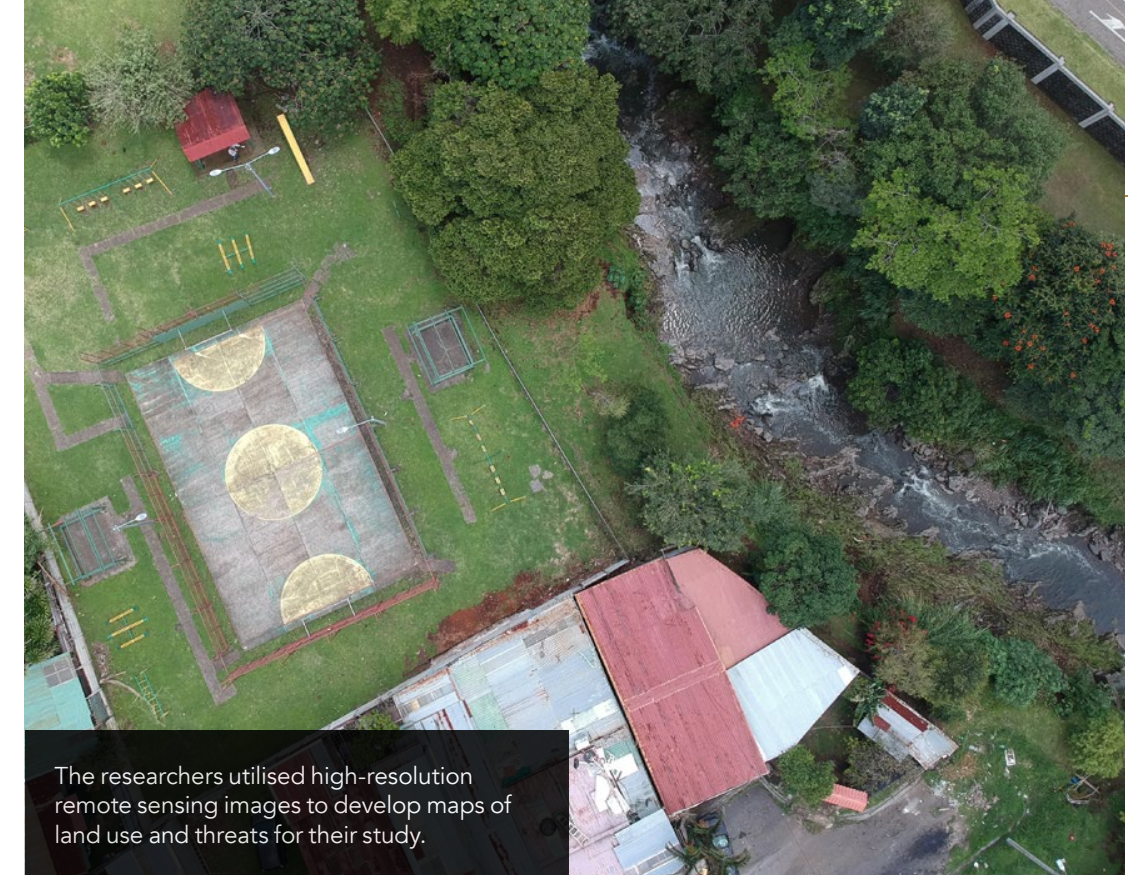

wildlife populations and preserve environmental cohesion over fragmented landscapes. In cities, rivers connect isolated wild ife populations with their However, many urban rivers are utilised as drainage resenvoirs for stormwater, wastewater disposal systems for factories or sewage plants, or energy producers, through the construction of hydroelectric dams. While these functions provide essential services to the cities' inhabitants (storm prevention, power production), they can disturb the natural ecological functions of the river corridor. Understanding freshwater ecosystem threats and having the ability to assess the health of river

corridors over time is essential to maintaining
biodiversity in urban environments. The IPBES report found agricultural and urban dwelling expansion to be two of the biggest drivers of habitat The health of a degradation over the last 50 years.

\section{MODELLING DEGRADATION} InVEST is a freely available open-source land use and human-derived threats. has thus far been applied to large-scale has thus far been applied to large scale habitat quality is defined as the ability of an ecosystem to provide conditions appropriate for population persistence, and 'high-quality' habitats are those with intact ecological functions. The model assumes that habitat quality decreases as the intensity of anthropogenic land on land use to calculate the quality of player in urats, making them a crucial

the sensitivity of the threatened area, to give the total threat level, or degradation for. A hegradidentified, for carculated built-up areas, road networks or pollution, and computed with the habitat suitability score to give overall habitat quality. period of time, or it mean be modelled a predictions about future scenarios, such as those involving megacities. Prediction scenarios can be used by governmental bodies to make informed decisions about quality in the future. to assess habita quality banction is Pr Jochen Hack, in collaboration with his Darmstadt, he Technical University of oxamine a smallscayed InVEST corridor in the city of León, Nicaragua, Central America. Prof Hack and his eam set out to assess the individual and combined impacts of anthropogenic threats, specifically, built-up areas, road

THE ANTHROPOGENIC AND POLLUTION

nis Nicaragua's second largest city, home to 180,000 inhabitants. The Pochote thwest direction through the city, and confluents with the Chiquito River outside the city's boundaries the Pacific Ocean. In their study Prof Hack nd his team selected

be assessed through the use of habitat type (for example, forest, grassland, that examine land use and biodiversity threats across specific areas. Although many habitat assessment tools have been developed over the past decade, few are freely available. As the regions expecting the largest population growth over the next thirty years are mainly confined to the developing world, where funding is short and ecological protection low on the agenda, free-ofcharge, accessible ecology assessment tools are paramount if the United Nation Sustainable Development Goal (SDG) 11 to make cities inclusive, safe, cropland, built-up) and the user defines conserving biodiversity. Suitability scor range between zero and one - the closer the score to zero, the lower the suitability and the lower the survival of species. Intact habitats, such as forests, wilhave a higher suitability score while modified habitats, such as cropland, wil exhibit lower scores.

The suitability score is then combined from the threat accessibility of the thresten inpact, the with threat parameters that describe the corridor of the Pochote river, composed of ength and representing different levels of

The researchers utilised high-resolution satellite images as input data for the development of raster maps for their model. When applying InVEST to (A) viroun were the most affected, with a buldings, of 0.3. As anticipated, the further away from the settlement, the lower the habitat three river branches, each one kilometer in urbanisation: densely urbanised, urbanriver in the n, the upper branches of the 
degradation; the southwest portions of the river, furthest away from the city's of (HO) by up to $40 \%$.

The team then examined river habitat degradation due to road networks. with the distribution and density of the settlements, with roads in built-up areas resulting in the biggest reduction in habitat quality, reducing the $\mathrm{HO}$ score in these zones to almost zero. Habitat quality was reduced most dramatically of the river, or where the road network invaded the river corridor via bridges.

Prof Hack then investigated the influence of water pollution on Pochote habitat ingacion. Water pollution was most waste disposal and leakage of untreated wastewater from upstream water

treatment plants. The threat due to river pollution in these zones was equivalent to that derived from built-up areas, with a HD score of 0.3 . As with built-up areas, the impact of river pollution decreased as the distance from settlements increased, though degradation from water pollutants emained in low levels throughout the course of the studied river section due to natural freshwater hydrodynamics carrying pollutants downstream.

When looking at the effects of combined hreats, the researchers found the highest of up to 0.85 ) in the upper (Nrancos the river, closest to densely settled areas. Fpeared to reduce river habitat quality The impact of the roads correlated where roads were present on both sides

Habitats in this area of the river had already been damaged or destroyed by buildings and roads, and the degraded water pollution.

\section{INVESTING IN OUR FUTURE}

Prof Hack and his team successfully used InVEST to assess the environmental degradation caused by buildings, roads and water pollution in León, Nicaragua. Their conceptual approach to assessing ecological health is accurate and rapid, has low data requirements, and is free of charge. These characteristics make InVEST a viable method for governmental bodies to use when identifying high-risk areas an conservation hotspots during city planning in developing regions. Prof Hack's versio of the model used in this study consider limited land use types and anthropoge threats focusing on urban aspects land use types such as protected areas and agricultural land use, and threats such as agricultural run-off contaminated by fertilizer or pesticides as well as industria wastewater discharge, would all ow a more comprehensive understanding of the ecological status of the study area. The model could also potentially be used to investigate particular species rather than biodiversity as a whole, in areas where

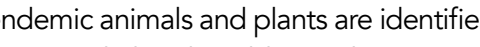
as particularly vulherable to urban and his team, they developed several novel methodologies such as MAPURES Methodology to Assess the Potential of Urban River Ecosystem Senvices), to investigate ecosystem senvices and nature-based solutions based upon field data and high-resolution true-color images obtained from Google Earth. Together, these methods shed light on the impacts of urbanisation on a previously unexplored river ecosystem and help to reveal the beneficial functions and services river provide to urban populations.

Overall, the trends in data derived from effect relationship between antropogen the InVEST model capable of modelling impacts of urban expansion on ecology in a developing country. The city of León is currently expanding its built-up zone into the urban-rural transitional area which will likely result in increased habitat degradation unless preventative action is taken. In this age of unprecedented environmental decline, every aspect of society's interactions with nature offers

\section{In this age of unprecedented} environmental decline, every aspect of society's interactions with nature offers the opportunity to cause further destruction, or pave the way toward a healthier future for all. this conceptual study suggest a cause-
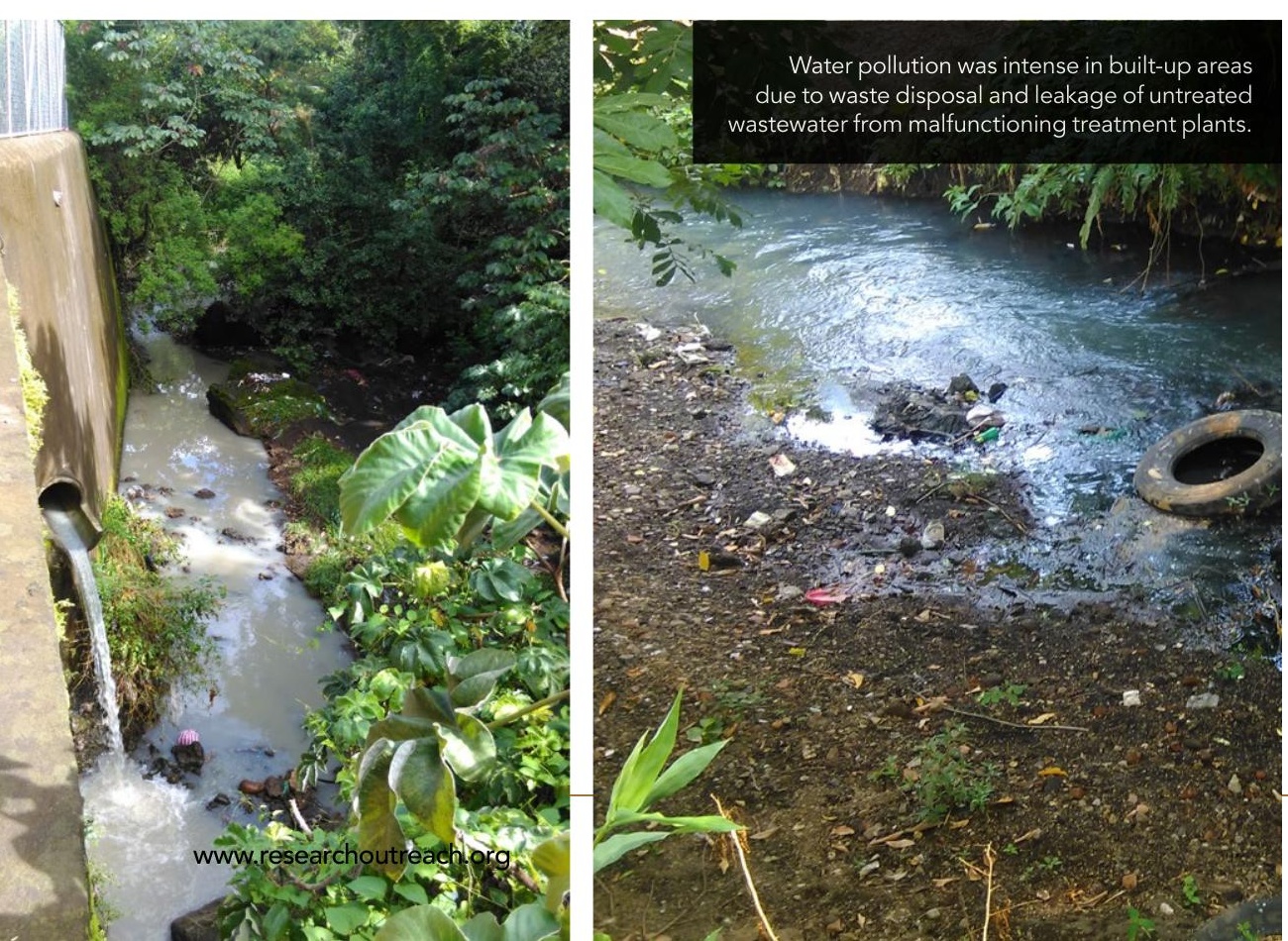

he opportunity to either cause further destruction, or pave the way toward a healthier future for all. This kind of detailed, high-resolution analysis is essential in understanding how we can limit the spatia distribution of anthropogenic impacts, and plan towards more sustainable cities by taking advantage of the bluegrovide Natucture that river corridors Phende. Nature-based solutions, such as design, or Berlin's creation of a 'green belt' re fantastic initiatives, but progress cannot be made without first understanding the nature of the problem. Models like Prof solution-led sustainable cities.

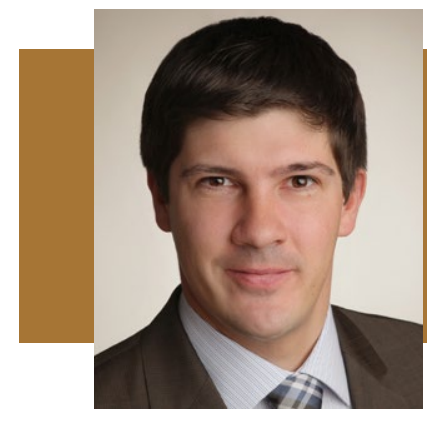

\section{Behind the Research}

\section{Prof Jochen Hack}

E: contact@geo.tu-darmstadt.de T: +496151 16-20981 ff seeurbanwater @ @ @seeurbanwater W: https://www.tu-darmstadt.de/see-urban-water/ W: https://www.geo.tu-darmstadt.de/ingenieuroekologie/index.en.jsp
Researchgate: https://www.researchgate.net/profile/Jochen-Hack

Research Objectives

Prof Hack examines the ecological state and societal importance of the Pochote river in León, Nicaragua. His research aims to reduce Detail Address
Technical University of Darmstadt
Section of Ecological Engineering chrittspahnstr 9

Bio Jochen Hack is Professor for Ecological
Engineering and Leader of the lnter- and

Transdisciplinary Research Group SEE-
URBAN-WATER at Technical University Darmstadt, Germany. He is an expert based Solutions, the study of Green Infrastructure and Ecosystem Services.
Prof Hack holds a PhD in Environmenta Engineering from Technical University

Funding German Federal Ministry of Educatio and research (BMBF), grant number

Collaborators - Diana Molewijk

\section{References}

Hack, J., Molewijk, D. \& Beissler, M. R. (2020). A Conceptual Approach to Modeling the Geospatial Impact of Typical Urban Sensing, 12, 1345. Available at: https:///doi.org/10.3390/ rs12081345

Beissler, M. R. \& Hack, J. (2019). A Combined Field and Remote-Sensing Based Methodology to Assess the Cosystem Service Potential of Urban Rivers in Developing Countries. Remoe Pensing

Chapa, F., Hariharan, S. \& Hack, J. (2019). A New Approach to High-Resolution Urban Land Use Classification Using Open Access Software and True Color Satellite Images
Sustainability, $11(19)$ 5266. Available at: https://doi org/10.3390/su11195266

ICLEI \& CBC. (2021). How cities are using nature-based Available at: https://bit.ly/3gPON5M

United Nations Department of Economic and Social Affairs. 2018). $68 \%$ of the world population projected to live in urban areas by 2050, says UN. [online]. Available at: https:// unw.un.org/development/desa/en/news/population/2018 evision-of-world-urbanization-prospects.htm

\section{Personal Response}

Would it be difficult to model specific species Wherability rather than total habitat quality II Modelling habitat suitability for specific species and their vulnerability to habitat degradation is more complex and requires more detailed data on the species, their
ecological networks, and their susceptibility to specific threats to be considered. While a total habitat focuses on characteristic ecological structures and processes (e.g., related to the provision of food, shelter, reproduction and breeding conditions in generall) and their susceptibility to specific theats, a species vilnerabity approach would species. For the latter, information is often much scarcer. II

Do you think results would differ if you modelled a developed chy, such as London, usying InVEST and the parameters described in your most recent study? II The result of modelling a developed city would certainly differ. Both habitat conditions and threats are usually different in more developed cities. River corridors and their development as rivers are increasingly channelised and engineered to convey runoff from urban areas faster and safer as well as to gain more space for urban development. This often results in a loss of natural floodplains and river corridor vegetation leading to degraded or lost habitat suitability. On the other hand, threats stemming from decrease with higher developments as treatment plants and waste collection systems are implemented and stronger
enforcement of environmental regulations are in place. 